\section{User-led research and evidence-based medicine}

\author{
ALISON FAULKNER and PHIL THOMAS
}

Evidence-based medicine (EBM) and clinical governance play a central role in raising the quality of medical care. People want clinical decisions to be based on the best evidence and EBM places scientific knowledge in the service of clinical decision-making. Yet a quite different agenda is engaging patients as partners in health research, to make the medical profession more accountable. Here, we examine the epistemological basis of EBM, and the ethical concerns raised by this. In particular, we examine the value of user-led research in psychiatry in improving the concept of 'evidence' in evidence-based psychiatry.

\section{MODERNISM AND EBM}

Medicine is now practised in a post-modern context that potentially conflicts with the modernist agenda of EBM. Although postmodernism does not mean rejecting modernism, it does mean that we should acknowledge modernism's drawbacks as well as its benefits. Modernism originated in the European Enlightenment with the quest for a self-evident truth free from doubt. The path to truth and knowledge was to be via science and rationality. Most historical accounts of psychiatry trace its origins back to the Enlightenment (Bracken $\&$ Thomas, 2001), with the subsequent sequestration of the insane in the asylums. As a result, madness came to be accounted for by the scientific and rational narratives of psychiatry, through the medical technologies of diagnosis and treatment.

A rational, scientific approach to therapeutic decision-making lies at the core of EBM. Hodgkin (1996) sees EBM as a modernist backlash against post-modernism in medicine, because it represents the modernist belief that treatment decisions can be based on an objective understanding of a universal reality. Laugharne (1999) also argues that the underlying philosophy of EBM is modernist, because it assumes that medical interventions always can be rational and measurable. Although EBM may be valuable in discriminating between the claims made by advocates of different treatments, patients are left feeling that their concerns are forgotten and that they are little more than a disease being treated. There are two possible ways forward. The first involves a debate about the values, power and assumptions that underlie psychiatric knowledge - what we have framed as "ethics before effectiveness" (Bracken $\&$ Thomas, 2000). The second attends to the concerns of service users, through user-led research.

\section{THE ETHICS OF EBM}

Although there are ethical arguments for EBM, it also raises serious ethical problems. First, it is a form of consequentialism: the proposition that the worth of an action can be assessed by measuring its consequences (Kerridge et al, 1998). Consequentialism may be acceptable if outcomes are easy to define and measure, and if doctor and patient are in agreement about the nature of the problem. But this is rarely so in psychiatry, where the internal experiences inherent in mental health problems, such as voices or delusions, are not amenable to objectification and quantification. Diagnoses themselves are contentious and based solely on personal accounts and observation. Outcomes such as quality of life may defy definition. Evidence-based medicine is ill-suited to resolve the resultant conflict because it is unable to reconcile the values and beliefs of different stakeholders. Second, doctors define distress in terms of psychiatric disorders; they determine research objectives, carry out research, interpret research data and implement research findings. Patients are expected to acquiesce in clinical decisions over which they have little control. Third, EBM may be at odds with common morality, because it assesses interventions in terms only of efficacy. It does not resolve how we should handle research evidence taken from unethical studies or unpublished studies that have no ethical safeguards.

There are also ethical concerns about modernism in psychiatry. Technological accounts of madness and the coercive role of psychiatry raise serious ethical issues for the rights of people whose freedom may be taken away and who may be forced to receive treatments they do not want (Bracken \& Thomas, 2001). The potential for coercion renders the failure to engage psychiatric patients in influencing research agendas even more significant, and demonstrates the importance of an ethical stance on EBM in psychiatry. We argue that the best way of achieving this is by involving service users in research.

\section{THE CASE FOR USER-LED RESEARCH}

General medicine now recognises the importance of patient involvement in research. In 1999 the Chief Medical Officer established an Expert Patients' Task Force to design self-management programmes for people suffering from chronic physical illness. According to Entwistle et al (1998), lay involvement in research is politically mandated because prevailing notions of democracy require that the general public, who ultimately provide funds, should influence research. Chalmers (1995) points out that basic research aimed at elucidating the causes of disease has attracted higher status and funding than applied health research that helps people make informed decisions about their treatment. He argues that the involvement of patients is essential in developing research that is relevant to patients and carers. It also improves the quality of research, by encouraging a more openminded approach as to which questions are worth asking, which forms of health care are worth investigating and which treatment outcomes matter.

\section{WHY USER-LED RESEARCH IS IMPORTANT}

In summary, there is political resistance to seeing psychiatric patients as experts and to their involvement as partners in helping to set research agendas, coupled with a dominance of clinical neuroscience in the psychiatric and allied journals. User-led research has developed out of frustration 
with this situation. Research undertaken by and with service users examines issues and outcomes that are relevant and meaningful to service users. To our knowledge there have been no papers published in psychiatric journals dealing with user-led research, despite the recent growth of highquality research in this area. We argue that there are several reasons why this must change.

\section{Research methodology}

The gold standard of scientific respectability in health service research - and the standard upon which evidence is evaluated - is the randomised controlled trial. This may be the accepted way of answering the question 'which is the effective treatment for condition X?', but people are complex subjects for investigative methods that befit the natural sciences. This raises questions about the interpretation and meaning of human behaviour, which is essential in understanding why the findings of quantitative studies may be less relevant in the real world. Why, for example, do many people choose not to take a drug whose efficacy may be wellestablished? Such questions can best be answered by qualitative research, which is ideally suited to the elaboration and description of personal experience and to establishing the meaning behind people's views or actions.

In pragmatic terms, the value of research evidence is only as good as the questions we ask. Are we asking questions relevant to service users - the people for whom the issue is most crucial? If the questions are inappropriate to start with, the results will be misleading. Clinical effectiveness, if restricted to the narrow definition of 'symptom relief', may fail to take into account relevant aspects of people's lives, aspects that may be crucial in determining an individual's decision to continue treatment, remain in contact with services or indeed survive.

User-led research challenges this by asserting that research should be based in the subjective, lived experience of emotional distress. This raises the issue of ecological validity, or the way in which research findings reflect, or fail to reflect, what happens in the real world. Redefining outcomes according to users' priorities can help to make greater sense of clinical research, improving its ecological validity. For example, research on drug interventions rarely takes sufficient account of what it is actually like to take the drug. If clinical drug trials paid closer attention to the lived experience of those who take these drugs, we would have a better understanding of issues such as 'non-compliance'.

\section{Presenting alternative explanatory frameworks}

The dominant paradigm in psychiatry renders the views of people with mental illness invalid and negates the person as an individual. The medical model leaves little space for the individual's explanation of why he or she experiences emotional distress (Barrett, 1996). User-led research creates a space for users' understandings of their problems, laying the foundations for alternative explanatory frameworks. When we consider how a diagnosis is made (selfreporting, behaviour), then this approach has intrinsic validity. User-led research primarily attends to what people say about their experience and relies on their selfdefined frameworks for understanding this experience, not on professional concepts of illness. This approach has major implications for services and treatment.

\section{Access to marginalised groups}

Modernist psychiatry regards itself as universal: applicable to all people at all times. Post-modern critiques challenge this view and open up space for the views and beliefs of marginalised and excluded groups. User-led research also endeavours to enable the views of marginalised communities to be heard alongside those of mainstream communities and to be given equal validity.

\section{POWER AND EMPOWERMENT}

A discussion of user-led research cannot take place without a consideration of the power differentials involved. Although the status of psychiatrists and patients differs vastly, so also does the status of different research methodologies within the research community. Furthermore, conventional academic and health services research provides career opportunities for professional researchers, potentially at the expense of their research subjects. In the meantime, service users and research participants are rarely paid for their 'involvement'.

User-led research, on the other hand, aims to do something different. By focusing on the research process as much as on the outcomes, it aims to enable service users to take part in carrying out research while gaining skills and confidence in the process. It aims to be inclusive and informative, ensuring that people who take part as research participants are kept fully informed of the results and of any action subsequently taken. This is rarely the case with traditional research.

\section{EXAMPLES OF USER-LED RESEARCH}

There are now many excellent examples of high-quality user-led research. We shall briefly consider two. Strategies for Living (Faulkner, 2000) was a qualitative study involving interviewing of 71 mental health service users. Designed and executed by service users, the research explored people's strategies for living and coping with mental distress. The predominant theme to emerge concerned the importance of relationships with others, especially family and friends, and people encountered at day centres and self-help groups. Peer support, the support of others in similar circumstances and the value of self-help received warm and grateful praise. The first experience of meeting others with similar problems, in a group or day centre, was often a significant turning point in people's lives, emphasising the value of acceptance and belonging against a background of stigma and discrimination. This suggests that practitioners should pay more attention to the role of self-help and peer support in overcoming stigma and discrimination. Mental health professionals should facilitate self-management, rather than prioritising interventions aimed at symptom eradication.

Rose (2001) has demonstrated the value of user-led research in defining standards of good practice in mental health care. In her study, user satisfaction was positively correlated with the amount of information provided, especially information about sideeffects of medication. User satisfaction was negatively correlated with the subjective experience of being overmedicated. The message is clear as far as psychiatric practice is concerned: good practice does not necessarily depend on rocket science. Simple things, such as ensuring access to high-quality information and taking steps to prevent overmedication, are very significant to service users. 


\section{CONCLUSIONS}

No matter how 'scientific' we aspire to be, clinical decisions always will involve value judgements and it is a serious mistake to pretend otherwise. This makes it essential that psychiatrists reflect critically on the values that underlie the advice they offer and the decisions they make, and that they understand how these values relate to those of patients. Placing user-led research on an equal footing with professional research enables professionals to think more carefully about the values behind scientific evidence. A marriage of two types of expertise is the essential ingredient of the best mental health care: expertise by experience and expertise by profession. Psychiatrists must work in alliance with service users to find ways of integrating user-led research with EBM. For this to happen, concepts of clinical governance must change. Psychiatrists should attach as much importance to userled research in the processes of clinical decision-making as they do to randomised controlled trials. This has implications for continuing professional development and the training of psychiatrists. It is time for greater openness between the profession

ALISON FAULKNER, MSc, Mental Health Foundation, London; PHIL THOMAS, FRCPsych, Bradford Community Health Trust and University of Bradford, Bradford

Correspondence: Phil Thomas, Level 3, Horton Park Centre, 99 Horton Avenue, Bradford BD7 3EG, UK. E-mail: p.thomas@bradford.ac.uk

(First received I8 January 200I, final revision 25 June 200I, accepted 6 July 200I)

and service users, in our academic departments, journals and scientific meetings. The Department of Health in setting national research and development policies in mental health must attach as much weight to 'partnership' research as it does to other health areas. To do otherwise is to discriminate against psychiatric patients.

\section{DECLARATION OF INTEREST}

None.

\section{REFERENCES}

Barrett, R. (1996) The Psychiatric Team and the Social Definition of Schizophrenia. Cambridge: Cambridge University Press.

Bracken, P. \& Thomas, P. (2000) Putting ethics before effectiveness. Open Mind, 102, 22.
- \& - (200I) Postpsychiatry: a new direction for mental health. British Medical Journal, 322, 724-727.

Chalmers, I. (1995) What do I want from health research and health researchers when I am a patient? $B M \mid, 310,1315-1318$.

Entwistle, V., Renfrew, M., Yearley, S., et al (1998)

Lay perspectives: advantages for health research. British Medical Journal, 316, 463-466.

Faulkner, A. (2000) Strategies for Living: A Report of User-Led Research into People's Strategies for Living with Mental Distress. London: Mental Health Foundation.

Hodgkin, P. (1996) Medicine, postmodernism, and the end of certainty. British Medical Journal, 313, 1568-1569.

Kerridge, I., Lowe, M. \& Henry, D. (1998) Ethics and evidence-based medicine. British Medical Journal, 316, $|15|-\mid 153$.

Laugharne, R. (1999) Evidence-based medicine, user involvement and the post-modern paradigm. Psychiatric Bulletin, 23, 641-643.

Rose, D. (200I) Users' Voices: The Perspective of Mental Health Service Users on Community and Hospital Care. London: Sainsbury Centre for Mental Health. 